\title{
Mixing zone regulation for effluent discharges into EU waters
}

1 Tobias Bleninger Dring

Group Leader Environmental Fluid Mechanics, Institute for Hydromechanics, Karlsruhe Institute of Technology, Karlsruhe, Germany
2 Gerhard H. Jirka PhD

Formally, Professor, Director, Institute for Hydromechanics, Karlsruhe Institute of Technology, Karlsruhe, Germany, now deceased

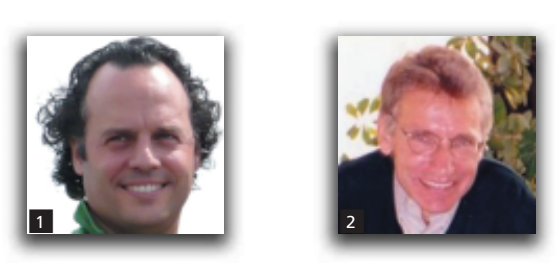

Environmental standards and their implementation in different countries are reviewed for point source discharges into surface waters. The paper focuses on the analysis of existing mixing zone regulations and recommends procedures to develop and manage mixing zone definitions as required by recent amendments of the 'combined approach' of the European Community water framework directive. The review shows that only a few mixing zone regulations exist in the European Union member countries, and that some effluent types, such as desalination brine discharges, and some discharge technologies, such as river diffusers, are not yet considered. The paper discusses those two issues in detail. First, by analysing desalination plant discharge characteristics and recommending mixing zone regulations for such multi-component and multi-process discharges. Second, by presenting river diffuser discharge technologies and procedures for demonstrating compliance of discharges that employ these technologies.

\section{Introduction}

Although considerable efforts have been made in Europe to install and upgrade wastewater treatment plants, there are still numerous inland and coastal water bodies not meeting the required 'good status'. This has been reported from each European Union (EU) member country after the mandatory monitoring phase as part of the European Community (EC) water framework directive (EC, 2000). Besides the necessary further investments in treatment facilities, and reduction of diffuse pollution sources, there are still strong concerns regarding the receiving water bodies themselves and their response to existing, upgraded or new discharges. The upcoming definition of measures to improve the water quality of all European waters until the year 2015 requires large investments and thus a good knowledge about the expected impacts and their interaction with other measures. Furthermore, monitoring campaigns require a good knowledge of substance distributions in the water body, to allow for optimal siting of monitoring stations and interpretation of monitoring data.

Point source discharges of wastewater, combined sewer overflows, cooling water, industrial waste and product water, and concentrate or brine discharges from desalination plants mix only slowly and often over long distances with the receiving waters. Resulting waste plumes may impact sensitive regions in aquatic ecosystems, and interact with other discharges or accumulate substances in enclosed locations. The 'combined approach' in the EC water framework directive (WFD) controls such discharges by setting environmental quality standards (EQS) in addition to emission limit values (ELV). Recent amendments (EC, 2008) of the WFD hereby corrected the previously missing definition and specification of regulatory mixing zones. EU member states and their water authorities are expected to develop or adopt regulatory mixing zone definitions and to implement those in national regulations until the year 2010 .

This paper helps to define where in the water body environmental quality standards should apply and which procedures shall be used for demonstrating compliance of such discharges. This is especially important for priority and emerging pollutants, or multi-component wastes for example from desalination plants. Furthermore, simple prediction methods for authorities and dischargers are referred to for a stringent and consistent discharge assessment.

The paper mainly discusses a desalination plant discharge, because of being a good example for a multi-component and multi-process type of discharge, wherefore no common standards have been developed up to now. 
In a second example, river diffuser systems and related regulations are presented, because those are also missing proper implementation and regulation. Definitions for further effluent types and discharge technologies can be deducted in a similar way or taken from previous studies for coastal discharges (Jirka et al., 2004a) and for river discharges (Jirka et al., 2004b).

\section{Discharge characteristics and mixing processes}

The discharge characteristics are defined by the characteristics of

(a) the built discharge structure, such as the type of the discharge structure (open channel, submerged/elevated pipe etc.), the site of the discharge structure (at the bank, in the water body, in the bay, close to breakwaters or groynes, etc.), the dimensions of the discharge structure (channel cross-section, pipe diameter, multiport installation etc.), the orientation of the discharge structure (discharge angles relative to prevalent currents or dominant geographical/bathymetrical features)

(b) the effluent, such as the type (municipal/industrial wastewater, combined overflow, drainage water, cooling water, desalination plant effluent), the physical properties (temperature, salinity, density, viscosity etc.), the fluxes (volume and momentum flux resulting from flow rate and discharge velocities), the chemical/biological properties (substance/bacteria concentrations etc.), the loads (yearly substance loads discharged).

The receiving water characteristics are defined by

(a) the local conditions near the discharge site, such as the type of water body (river, lake, coast etc.), the topography (meandering river, coastal bay etc.), the bathymetry (slopes, shallowness etc.), the physical properties (temperature, salinity, density, velocities etc.), the metereological/ hydrological conditions (flow, velocity and water level variations, density variations, reversing/non-reversing flows etc.), the chemical/biological properties (background concentrations, water quality conditions, natural assimilation capacities etc.)

(b) the regional conditions for the whole water body or parts of it, such as the proximity to other environmental pressures (other discharges, morphological changes, dams, backwaters etc.), the proximity to sensitive aquatic ecosystems (mangrove forests, salt marshes, coral reefs, or low energy intertidal areas and shallow coasts), the general flushing characteristics (residence times, exchange times).

In order to illustrate these ambient/effluent interactions, the example of a brine discharge into coastal waters is presented as follows. Brine (or concentrate) is the waste stream produced by desalination plants and is usually discharged into the sea. The brine discharge rate is generally up to $40 \%$ (for membrane-based technologies such as reverse osmosis (RO)) and up to $90 \%$ (for thermal technologies such as multi-stage-flash (MSF), including cooling water) of the intake flow rate and almost as large or considerably larger than the required freshwater product flow. The brine is characterised by its high concentration of substances taken out of marine waters (i.e. salt). Furthermore, and often more critical, the brine contains additives and corrosion products. Additives are chemicals used for biofouling control (e.g. chlorine), scale control (antiscalants), foam reduction, and corrosion inhibition that are added during the desalination process and discharged into the coastal waters as contaminants (Lattemann and Höpner, 2003). In addition, next to the high salinity and contaminants, the brine effluent might also show increased turbidity and temperature (the former mainly applies to RO, the latter mainly to MSF plants).

Major problems arise owing to the strongly limited mixing behaviour in the receiving waters. This behaviour is significantly influenced by the effluent density, which, in turn, is dominated by the varying effluent salinity and temperature. Variation in the density difference between the brine and the receiving water represented by the buoyancy flux, cause different flow behaviour of the discharge. The dense RO effluent flow has the tendency to flow as a density current (Figure 1(a)) or fall as a negatively buoyant plume (Figure 2(a)). The MSF effluent is distinguished by a neutral to positive buoyant flux causing the flow to spread at the surface (Figure 1(b)) or the plume to rise (Figure 2(b)). The impacts of these pollutants and brine characteristics on the marine environment can be manifold and are usually mitigated by technical measures.

Figure 1 illustrates the traditional discharge solution simply discharging through an open channel at the shoreline. This solution has major disadvantages owing to its siting at usually sensitive near-shore regions and due to its limited mixing characteristics, causing highly concentrated plumes at the bed or the surface and slow mixing with background motions. The mixing performance is hereby measured as a dilution value, a measure for the concentration reduction, generally defined as reciprocal volume fraction of effluent in a sample (total volume of sample/ volume of effluent in a sample).

Figure 2 instead illustrates optimised submerged offshore discharge solutions, conveying the effluent into less sensitive regions and applying efficient mixing technologies for enhanced dispersion, and, furthermore, utilising natural purification processes. Multiport diffuser outfalls designed as efficient mixing devices installed at locations with high transport and purification capacities are capable of significantly reducing environmental impacts. Two regions of impact are generally distinguished: the near-field and the far-field. The 'near-field' of a sea outfall is governed by the initial jet characteristics of momentum flux, buoyancy flux and outfall geometry as these influence the effluent trajectory and mixing. Outfall designers can usually affect the initial mixing characteristics through appropriate manipulation of design variables. In the 'far-field', ambient conditions will control trajectory and dilution through buoyant spreading motions, passive diffusion and advection by the usually time-varying velocity field. 
Water Management

Volume 164 Issue WM8
Mixing zone regulation for effluent

discharges into EU waters

Bleninger and Jirka
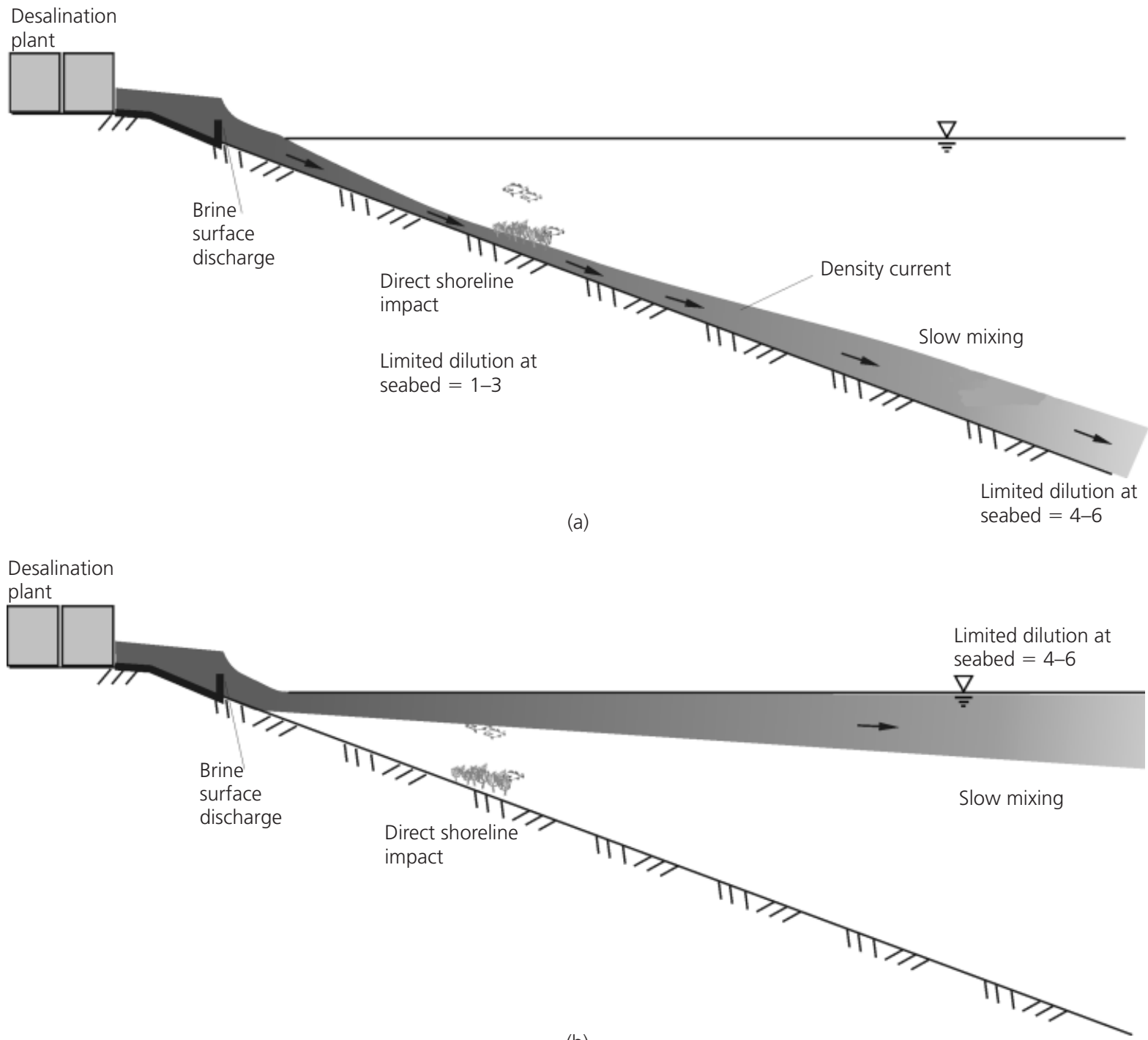

(b)

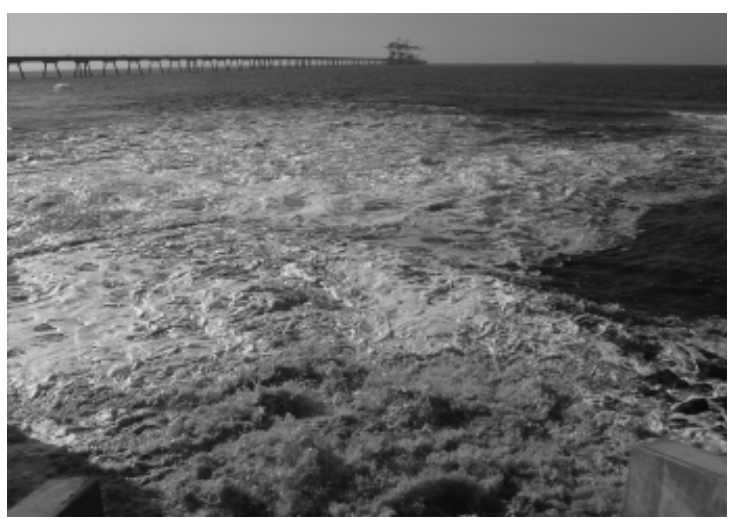

(c)

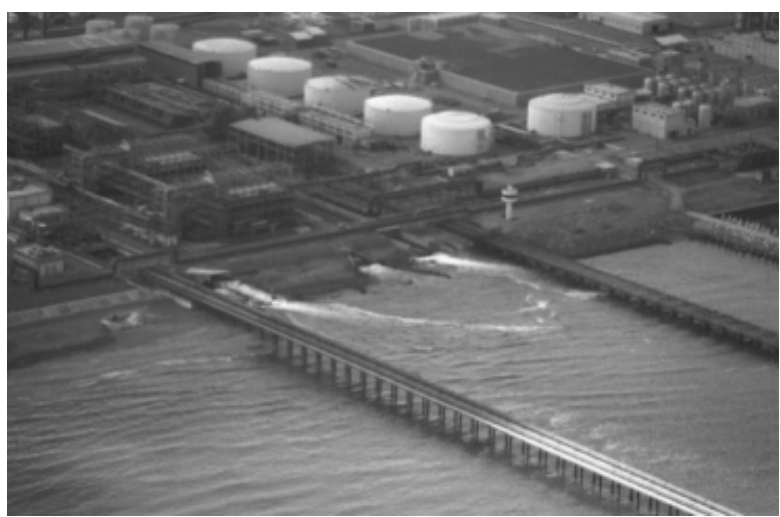

(d)

Figure 1. Mixing characteristics and substance distributions for shoreline brine discharge configurations by way of channel or weir: (a) RO plant (dense effluent); (b) thermal plant (dense effluent mixed with buoyant cooling water); (c) Ashkelon RO desalination plant (Israel) showing dense brine discharge during backwash through an open channel at the coast into the Mediterranean (photograph courtesy of R. Amir); (d) Al Ghubrah thermal desalination plant discharge through an open channel at the beach into the Gulf of Oman (photograph courtesy of H. H. Al-Barwani) 


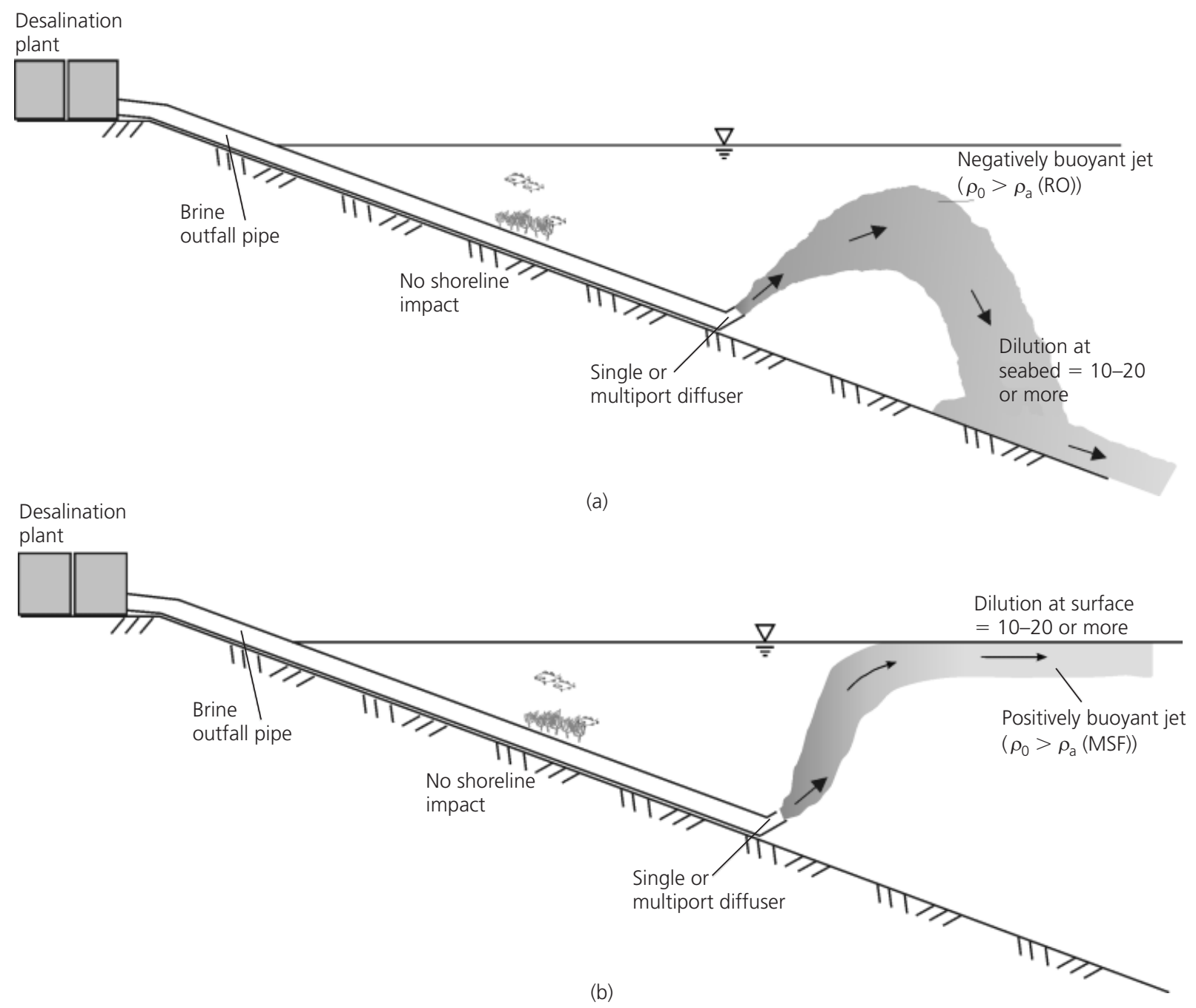

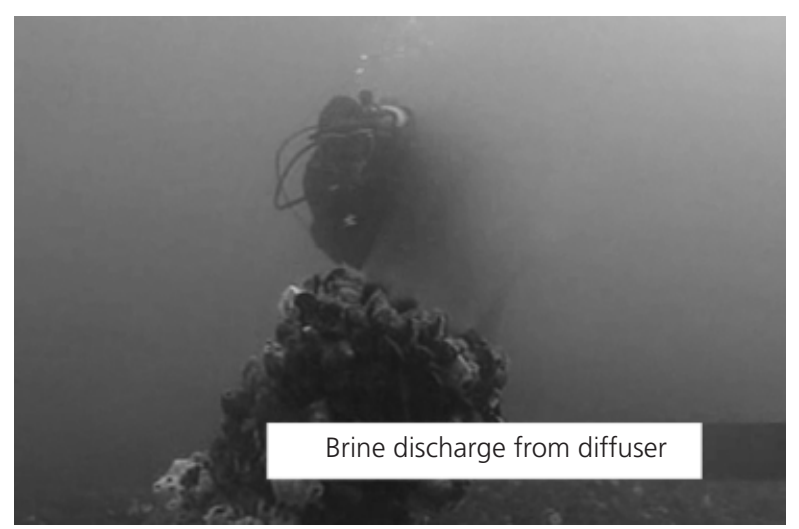

(c)

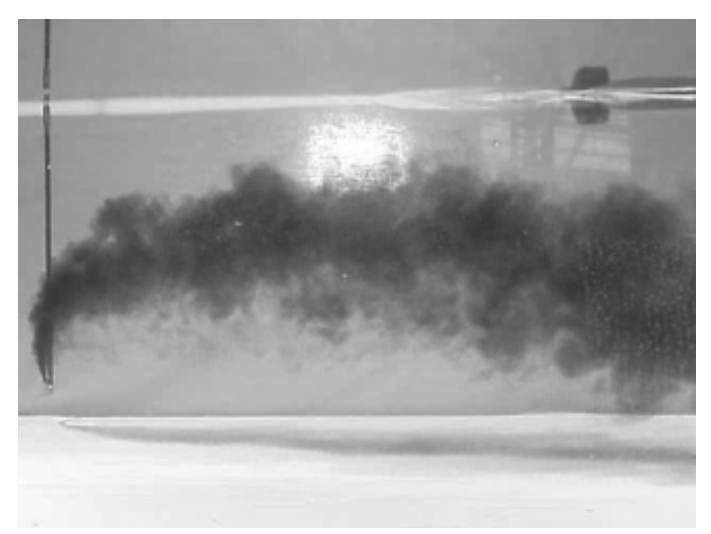

(d)

Figure 2. Sideviews of submerged discharges by way of pipeline and nozzle with a single or multiport diffuser for two effluent types: (a) negatively buoyant (RO plant) and (b) positively buoyant (thermal plant). (c) One discharge port of the multiport diffuser of Perth seawater desalination plant (RO), oriented $60^{\circ}$ upwards. The discharge can be seen by the changed refraction of the diver in the background (courtesy: Water corporation Australia, 'From ocean to tap', Jude Cotter). (d) Laboratory set-up visualising an optimised dense brine discharge resulting from an RO plant. Discharge is oriented $45^{\circ}$ upwards, and advected by the ambient current from left to right, but still descending towards the bed (lower edge of frame) 
In total, the discharge plume and associated concentration distributions generated by a continuous efflux from a sea outfall can display considerable spatial detail and heterogeneities as well as strong temporal variability, especially in the far-field. This has great bearings on the application of any water quality control mechanisms or monitoring issues.

\section{Environmental standards}

The 'combined approach' in the EC WFD controls point-source discharges by setting EQS in addition to ELV. The former encourage source control principles, effluent treatment and recycling technologies. The latter require the consideration of the ambient response often associated with the concept of the 'mixing zone', an allocated impact zone in which the numerical water quality standards can be exceeded (Jirka et al., 2004a, 2004b). ELV are preferred from an administrative perspective because they are easy to prescribe and to monitor (end-of-pipe sampling). From an ecological perspective, however, a quality control that is based on ELV alone appears illogical and limited, since it does not consider directly the quality response of the water body itself and therefore does not hold the individual discharger responsible for the water body. To illustrate that point consider a large point source on a small water body or several sources that may all individually meet the ELV but would accumulatively cause an excessive pollutant loading. EQS, set as concentration values for pollutions or pollutant groups, that may not be exceeded in the water body itself (EC, 2000) have the advantage that they consider directly the physical, chemical and biological response characteristics owing to the discharge and therefore they put a direct responsibility on the discharger. But a water quality practice that would be based solely on EQS could lead to a situation in which a discharger would fully utilise the assimilative capacity of water body up to the concentration values provided by the EQS. Furthermore, the water quality authorities would be faced with additional burdens because of a more difficult monitoring - where in the water body and how often to be measured? - in the case of existing discharges or due to the increased need for a prediction modelling in the case of new discharges. The 'combined approach' as described in the European WFD (EC, 2000) combines the advantages of both of these water quality control mechanisms while largely avoiding their disadvantages.

Concentration limits for ELV and EQS can be found in national, EU and international legislations for different substances and discharge and environmental characteristics. An example is listed for desalination plant discharges, because there are only few common standards available, but it is necessary to develop those in the near future. The most relevant water quality parameters for seawater desalination plant effluents are salinity, temperature, $\mathrm{pH}$, dissolved oxygen, turbidity, dissolved organic matter and residual chemical pollutants such as copper, nickel, residual-free chlorine and chlorinated by-products. It is beyond the scope of this paper to provide an overview on emission and immission limit values for all of these parameters at a global or European scale. These may be found in the new substance lists of the EC (EC, 2008) or in national or international standards. Presented below are selected standards for desalination brine discharges into coastal waters, mainly because such standards are under development for the Mediterranean region and common agreements should be achieved.

\subsection{Temperature}

A common ELV for temperature is $10^{\circ} \mathrm{C}$ above ambient (e.g. Sultanate of Oman, 2005). For an EQS the World Bank recommends, for example, that the water temperature does not result in an increase greater than $3^{\circ} \mathrm{C}$ above ambient temperature at the edge of a scientifically established mixing zone, which takes into account ambient water quality, receiving water use, potential receptors and assimilative capacity among other considerations (World Bank Group, 2007). For effluents from thermal power plants, the Pollution Prevention and Abatement Handbook (World Bank Group, 1998, which is currently under review) recommends to use $100 \mathrm{~m}$ from the point of discharge when there are no sensitive aquatic ecosystems within this distance.

\subsection{Salinity}

Similar to thermal 'pollution', increased salt concentrations can be harmful and even lethal to marine life. In general, toxicity depends on the sensitivity of the species to increased salinity, the natural salinity of their habitat and the life-cycle stage. The following standards have been summarised in Lattemann and Höpner (2003).

(a) The Western Australian guidelines for fresh and marine waters (Western Australia EPA, 1993) specify that the median salinity increase is to be less than 5\% above the background values. This corresponds to a change of 2 parts per thousand (ppt) in marine environments with a salinity of $40 \mathrm{ppt}$. The criteria for the concentrate discharge set by the Western Australia Environmental Protection Authority (EPA) for the Perth seawater reverse osmosis (SWRO) plant (Western Australia EPA, 2002) require that salinity is within 1.2 units of ambient levels within $50 \mathrm{~m}$ of the discharge point and within 0.8 units of background levels within $1000 \mathrm{~m}$ of the discharge point. The initial dilution usually occurs within the $50 \mathrm{~m}$ radius, and would require a initial dilution of 45 or above for that location.

(b) In the US, California State recommendations (City of Carlsbad, 2005) state that salinity variations from natural levels should not exceed 4 units from natural variation in areas permanently occupied by food and habitat forming plants when natural salinity is between $13.5 \mathrm{ppt}$ and $35 \mathrm{ppt}$. This corresponds to an increase in salinity between $11 \%$ and $39 \%$ above background levels.

(c) According to Omani regulations on the discharge of liquid waste into the marine environment, the salinity should not deviate from the surrounding average for more than 2 units on a daily basis in a circular area of $300 \mathrm{~m}$ diameter around the point of discharge (Sultanate of Oman, 2005). 
(d) For Mediterranean Posidonia oceanica seagrass meadows, salinity thresholds have been recommended based on field and laboratory experiments. Salinity should not exceed a value of $38.5 \mathrm{ppt}$ in any point of a seagrass meadow for more than $25 \%$ of the observations (on an annual basis) and should not exceed a value of $40 \mathrm{ppt}$ in any point of the meadow for more than $5 \%$ of those observations. This threshold applies to Posidonia oceanica of the western Mediterranean and requires verification by further studies (Sánchez-Lizaso et al., 2008). Ambient salinities in the western Mediterranean range between 37 and 38 ppt.

\subsection{Chemicals}

The World Bank Pollution Prevention and Abatement Handbook (World Bank Group, 1998) recommends the following maximum values for effluents from thermal power plants. The ELV effluent levels should be achieved daily without dilution. The values may also be applied to thermal desalination plants due to similarities in effluent properties. The most relevant parameters are probably residual chlorine and copper (see Table 1).

\begin{tabular}{lc}
\hline Parameter & Maximum value \\
\hline Total residual chlorine & $0.2 \mathrm{mg} / \mathrm{l}$ \\
Copper & $0.5 \mathrm{mg} / \mathrm{l}$ \\
Iron & $1.0 \mathrm{mg} / \mathrm{l}$ \\
Zinc & $1.0 \mathrm{mg} / \mathrm{l}$ \\
Chromium (total) & $0.5 \mathrm{mg} / \mathrm{l}$ \\
Oil and grease & $10 \mathrm{mg} / \mathrm{l}$ \\
pH & $6-9$ \\
Total suspended solids (TSS) & $50 \mathrm{mg} / \mathrm{l}$ \\
Table 1. Maximum ELV values for effluents from thermal power \\
plants (World Bank Group, 1998)
\end{tabular}

The US EPA National Recommended Water Quality Criteria (US EPA, 2006) contain recommended water quality criteria for the protection of aquatic life in fresh and marine waters for approximately 150 pollutants. These include the criteria maximum concentration (CMC) and the criterion continuous concentration (CCC), which are estimates of the highest concentration of a substance in surface water to which an aquatic community can be exposed briefly (CMC) or indefinitely (CCC) without resulting in an unacceptable effect. The criteria are intended to be protective of the vast majority of the aquatic communities in the United States. As recommended by Lattemann and Höpner (2003), some of the parameters are relevant to desalination plant discharges, and may serve as an indication for regulating these discharges in other parts of the world (Table 2).

\section{Regulatory mixing zone}

The relevant values for ELV and EQS for various pollutants and pollutant groups have been described above for a few examples. Table 3 contains the values for two chemical pollutants (copper and chlorine). The ratio ELV/EQS is 104 for copper and 27 for chlorine. The ratio of above listed concentration limits, ELV/EQS, is generally within a range of 5 to 1000 for most chemical as well as physical parameters, such as heat (temperature). This ratio describes the impact of the pollutants on the ecosystem, since the ELV is considered to protect against acute (lethal) effects on organisms, while the EQS is supposed to prevent long-term chronic influences.

The ratio also expresses the necessary dilution that must be attained through physical mixing or - to some extent - through biological decay and chemical transformation processes. Point source discharges generally mix slowly with surrounding waters over long distances.

Usually a regulatory mixing zone concept is applied to avoid high concentrated plumes over long distances and impacts with

Parameter

\section{Chlorine}

Copper

Iron

Zinc

Chromium (VI)

Nickel

Cadmium

Lead

Oil and grease

Dissolved oxygen (DO)

Total suspended solids (TSS)

$\mathrm{pH}$

CMC $\quad$ CCC

\begin{tabular}{|c|c|}
\hline \multicolumn{2}{|l|}{$13 \mu \mathrm{g} / \mathrm{l}$} \\
\hline $4.8 \mu \mathrm{g} / \mathrm{l}$ & $3.1 \mu \mathrm{g} / \mathrm{l}$ \\
\hline \multicolumn{2}{|c|}{ Not given } \\
\hline $90 \mu \mathrm{g} / \mathrm{l}$ & $81 \mu \mathrm{g} / \mathrm{l}$ \\
\hline $1100 \mu \mathrm{g} / \mathrm{l}$ & $50 \mu \mathrm{g} / \mathrm{l}$ \\
\hline $74 \mu \mathrm{g} / \mathrm{l}$ & $8.2 \mu \mathrm{g} / \mathrm{l}$ \\
\hline $40 \mu \mathrm{g} / \mathrm{l}$ & $8.8 \mu \mathrm{g} / \mathrm{l}$ \\
\hline $210 \mu \mathrm{g} / \mathrm{l}$ & $8.1 \mu \mathrm{g} / \mathrm{l}$ \\
\hline
\end{tabular}

Narrative statements, see (US EPA, 2006)

Narrative statements, see (US EPA, 2006)

Narrative statements, see (US EPA, 2006)

$6 \cdot 5-8 \cdot 5$

Table 2. US EPA (2006) National recommended water quality criteria for selected pollutants 


\begin{tabular}{lrrr}
\hline Pollutant example & Emission standard (ES) & Ambient standard (AS) & ES/AS \\
\hline $\begin{array}{l}\text { Copper } \\
\text { Chlorine }\end{array}$ & $500 \mu \mathrm{g} / \mathrm{l}$ (World Bank Group, 1998) & $4.8 \mu \mathrm{g} / \mathrm{l}$ (US EPA, 2006) & 104 \\
Table 3. Examples for emission limit values (ELV) and & $7.5 \mu \mathrm{g} / \mathrm{l}$ (US EPA, 2006) & 27 \\
environmental quality standards (EQS) for two selected pollutants & & \\
\hline
\end{tabular}

sensitive regions. The original WFD (EC, 2000) was missing such specifications or recommendations as to where in the water body the EQS should apply and which procedures shall be used for compliance of discharges. However, very recent amendments (EC, 2008) will improve its administrative implementation, where Article 4 (1) defines

Member States may designate mixing zones adjacent to points of discharge. Concentrations of one or more substances listed in Part A of Annex I may exceed the relevant EQS within such mixing zones if they do not affect the compliance of the rest of the body of surface water with those standards.

Furthermore, designated mixing zones will be included in river basin or coastal zone management plans, including approaches and methodologies applied to define such zones. Criteria for the spatial location and extent of the mixing zones are defined in Article 4 (3). They should be

(a) restricted to the proximity of the point of discharge;

(b) proportionate, having regard to the concentrations of pollutants at the point of discharge and to the conditions on emissions of pollutants contained in the prior regulations, ...

Member states and their water authorities are now required to develop technical guidelines for the identification of mixing zones in accordance with the regulatory procedure and to implement those in national regulations until the year 2010. The mixing zone defined in the above statement is a regulatory formulation with the following general attributes.

(a) The term 'mixing zone' signifies explicitly that mixing processes require a certain spatial extent within which mixing processes operate.

(b) The term 'restricted' should guarantee that the mixing zone shall be minimised by the regulatory authority for the purpose of attaining the environmental quality goals.

(c) While the mixing zone includes a portion - namely the initial one - of the actual physical mixing processes, these processes will continue beyond the mixing zone where they lead to further concentration drop-offs in the pollutant plume below the ES-values.

(d) The definition is restricted to 'point sources' since diffuse sources usually do not contain such clearly distinct mixing processes.

The regulatory concept of mixing zones is nothing new in an international context, and can also be found in the water quality regulations of other countries (e.g. US EPA, 1994). However, it is a new concept for most European countries, where the ELV approach alone has mainly been applied in the past. The additional application of the EQS now promises further water quality improvements, if applied seriously.

The authors therefore recommend the following specifications, made on the basis of $(a)$ existing regulations in other countries, (b) good knowledge of physical mixing and transport processes for different water bodies and $(c)$ feasibility regarding existing monitoring and prediction instruments.

The recommendations are separated into discharges into coastal waters and discharges into inland waters. Inland waters, such as lakes and rivers, are common receiving waters for effluent discharges. In general, discharges into small lakes should be avoided, owing to their very limited assimilation capacities and the risk of substance accumulation. Discharges into large lakes can be analogously treated as discharges into coastal waters if special consideration is given to the limited flushing characteristics, and low velocities and low mixing potential of such water bodies.

Figure 3 shows definitions of regulatory mixing zones for river discharges. The specification of the numeric mixing zone dimensions should be done according to water body type and biological characteristics. The width of the mixing zone $B_{\mathrm{MZ}}$ can be restricted to a fraction of the river width, for example $B_{\mathrm{MZ}}=n_{\mathrm{B}}$ $B$, with the goal that the majority of the river cross-section provides for unhindered passage of river fauna (fish). Or the length of the mixing zone $L_{\mathrm{MZ}}$ can be described, for example $L_{\mathrm{MZ}}=n_{\mathrm{L}} B$, with the goal that high concentrations along the river banks are constrained, or both prescriptions may apply jointly. The multiples $n_{\mathrm{B}}$ and $n_{\mathrm{L}}$ - with typical ranges $n_{\mathrm{B}}=0 \cdot 1$ to 0.5 and $n_{\mathrm{L}}=1$ to $5-$ may be set by the water authorities based on regional considerations taking into account water body type, water use and biological characteristics. Figure 3 furthermore illustrates the different technological solutions available. Submerged discharges at some distance from the banks hereby improve the initial mixing and protect sensitive river banks. Further application of multiport diffusers allow the considerable reduction of the concentrations after short distances, thus improving natural degradation processes. Figure 4 shows definitions of regulatory mixing zones for coastal discharges or discharges into large lakes. Owing to the existence of multi-directional flows and usually more sensitive banks close to shore, shoreline discharges should be avoided for coastal discharges. 


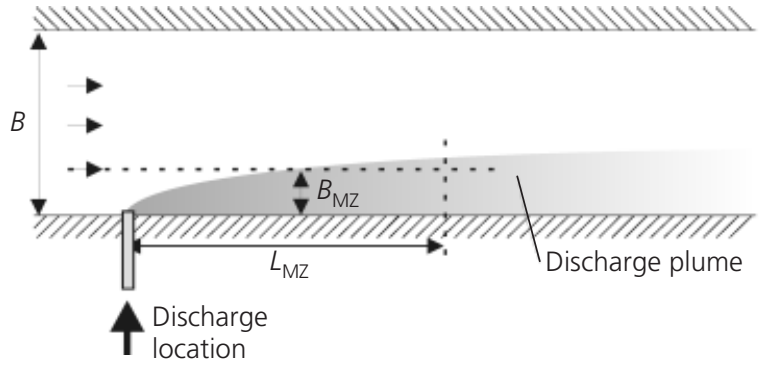

(a)

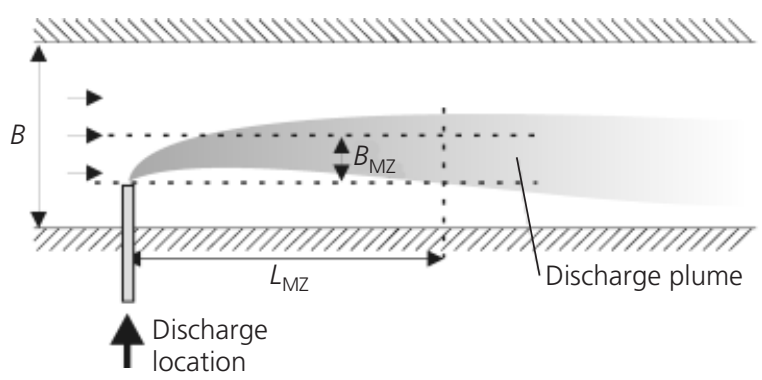

(b)

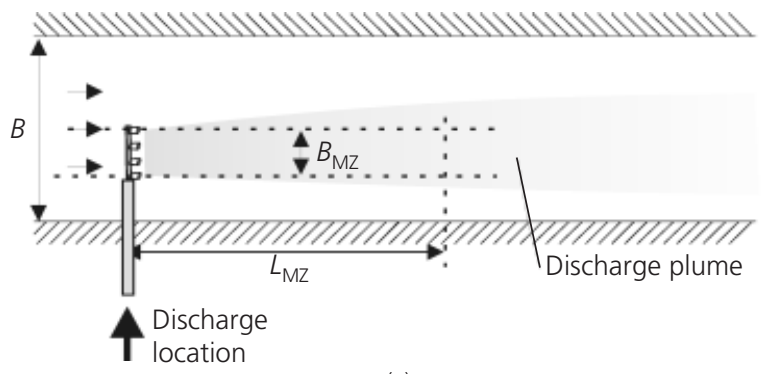

(c)

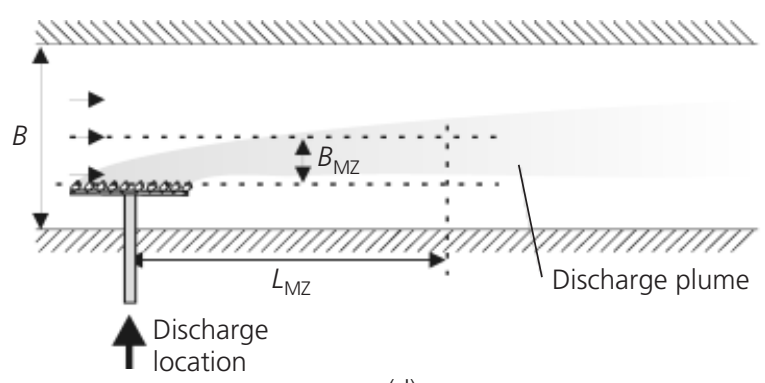

(d)

Figure 3. Examples of regulatory mixing zone specifications for river discharges, using a width limitation $B_{\mathrm{Mz}}$, and/or a length limitation $L_{M z}$, both defined relative to the river width $B$. (a) shows a traditional shoreline discharge, (b) a submerged offshore single port discharge, (c) a regular perpendicular diffuser design, and (d) a diffuser design for navigated rivers or rivers with other crosssectional limitations

The specification of the numeric mixing zone dimensions should be done according to water body type and biological characteristics. In the case of sea outfalls it seems advisable to constrain the mixing zone to a limited region around the outfall in which the initial buoyant jet mixing is dominant. In that fashion the EQS-values can be achieved within short distances. Thus the

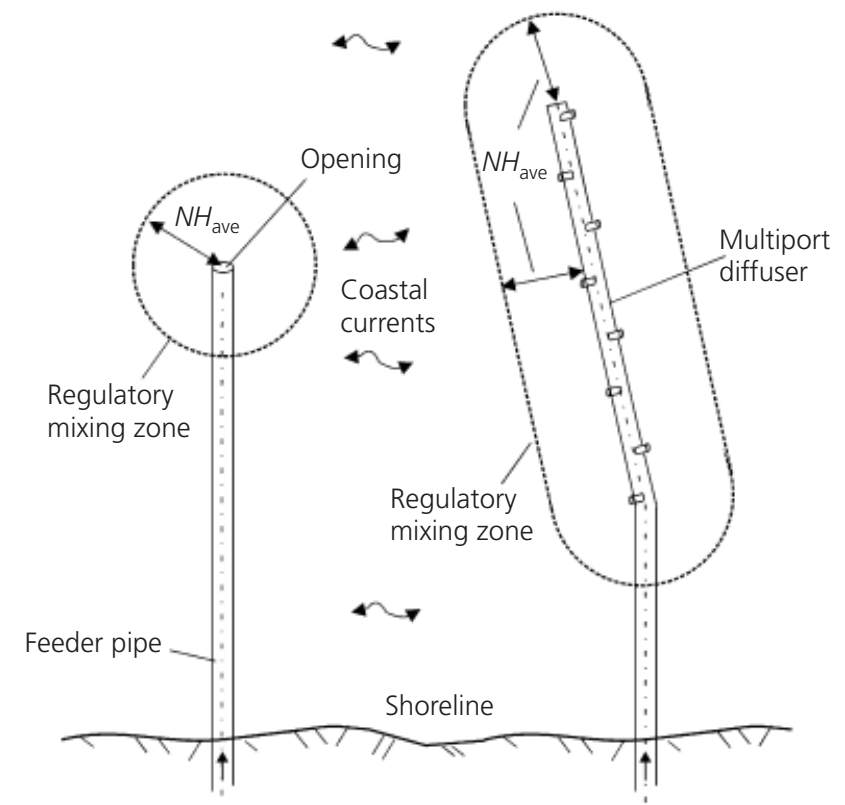

Figure 4. Examples of regulatory mixing zone specifications for offshore submerged coastal discharges ((a) and (b)) where the horizontal extent of the mixing zone is defined by some multiple $N$ of the average water depth $H_{\text {ave }}$ at the sea outfall: (a) single port outfall; (b) multiport diffuser sea outfall

following specification appears effective: 'The mixing zone is a volume with vertical boundaries in the coastal water body that is limited in its horizontal extent to a distance equal to $N$ multiples of the average water depth $H_{\text {ave }}$ at the outfall location and measured in any direction from the outfall structure.'

Thus, for a single port outfall this would be a cylindrical volume with the port in its centre (Figure 4(a)). For a multiport diffuser outfall with many ports arranged along a straight diffuser line it would be a rectangular prismatic volume with attached semicircular cylinders at the diffuser ends located along the diffuser line (Figure 4(b)). For diffusers with a curved diffuser line or piecewise linear sections the volume would follow the diffuser line. The value $N$ would typically be in the range of at least 1 to about 10 and set by the regulatory authority according to local water use and ecological sensitivity. For highly sensitive waters the minimum of 1 should be set. Common values for most coastal waters might be $N=2$ to 3 .

For desalination discharges in Oman for example, a fixed mixing zone of $300 \mathrm{~m}$ around the outfall is specified (Sultanate of Oman, 2005). In addition it is required that the outfall pipes must not be installed less than $1 \mathrm{~m}$ from the lowest tide line and the discharge pipes must be located in a place where it is impossible for the waste plume to hit corals and seaweed at the bottom.

Furthermore, specification of mixing zone dimensions can be defined in an ad hoc manner. After prior ecological evaluations or 
predictions the discharger can request the authority for a mixing zone with a certain dimension with the claim that this would guarantee an integrated water quality protection. Based on its own examinations, the authority can agree with that proposal or demand further restrictions.

\section{Discharge design considerations}

The design of a discharge structure should follow the following two general principles.

(a) The discharge siting. In this principle, the discharge location should be chosen in less sensitive regions. Avoid discharges in sites where direct and immediate impacts are to be expected, such as in environmentally sensitive or even environmentally protected sites, such as nearby coral reefs, in lagoons, in enclosed bays, within or nearby mangrove regions for discharges into coastal waters, or groyne fields, backwaters for discharges into rivers. The discharge location should be chosen in regions with good transport and flushing characteristics to avoid accumulation and allow for further mixing. Avoid discharges in sites with stagnant flows or enclosed, protected regions, such as between structures for erosion protection or wave-breakers, lagoons, harbours or very shallow waters with low current velocities.

(b) The discharge design. The discharge structure should be designed to avoid any direct or immediate impact with nearby boundaries. Therefore designs should be oriented into the open water body and not against the bed or the water surface, not cause strong bed or surface interactions, and not be concentrated at one single point. The discharge structure should be designed to enhance effluent mixing. Therefore designs should allow for energetic discharges to allow for strong initial mixing, be oriented perpendicular or co-flowing to predominant ambient currents and optimally distribute the effluent within the water body.

The above design objectives can be met for offshore/offbank, submerged, multiport diffusers. The offshore location provides the necessary distance to sensitive region. Submerged discharges allow for improved mixing before interacting with boundaries and multiport diffusers guarantee enhanced mixing. The above objectives should be considered for several siting and design alternatives to find optimal and cost-efficient solutions.

In order to demonstrate compliance with EQS standards for discharge consent, it appears that both dischargers as well as water authorities must increase the application of quantitative predictions of substance distributions in water bodies (water quality parameters in general, mixing processes in particular). This holds for both existing discharges (diagnosis) as well as planned future discharges (prediction).

There are several diagnostic and predictive methodologies for examining the mixing from point sources and showing compliance with EQS-values. (a) Experiments. Field measurements or tracer tests can be used for existing discharges in order to verify whether EQS-values are indeed met. Hydraulic model studies replicate the mixing process on a small scale in the laboratory. They both are costly to perform and inefficient for examining a range of possible ambient/discharge interaction conditions.

(b) Simple analytical equations or nomograms (e.g. Jirka, 2004, 2006, 2008, for coastal discharges, and Rutherford (1994) for river discharges) are often satisfactory to predict reliably the mixing behaviour of a pollutant plume. They give very fast a first estimate about the discharge conditions and are very easy to handle, therefore especially useful for the design purpose of discharge structures.

(c) Models. Mixing zone models are simple versions of more general water quality models. They describe with good resolution the details of physical mixing processes (mass advection and diffusion), but are limited to relatively simple pollutant kinetics. However, this is acceptable for most applications, since residence times in the spatial limited mixing zones are typically short so that chemical or biological mass transformations are usually unimportant.

(d) General multi-dimensional water quality models may be required in more complex situations, but the calculations are time intensive and expert knowledge is mandatory. Such studies are done once the first plant drafts have been developed and detailed environmental impact assessments considered. For example the application of the mixing zone model Cormix in combination with a water quality and flow model Delft3D has been covered for brine discharges (Niepelt et al., 2008).

\section{Conclusion}

The European member states are required to develop mixing zone regulations and define mixing zone extensions for point source discharges into their inland and coastal water bodies until 2010. Some authorities are reluctant to undertake the additional work to implement the mixing zone concept. However, it has been shown that clear methodologies and experience exist to define mixing zones, and simple approaches could be used to control the dischargers. Moreover, the combined approach of emission limit values and environmental quality standards promises to improve the water quality of European waters.

Specific examples and recommendations have been given for desalination plant discharges, where high initial dilution values, thus efficient multiport diffuser outfalls, are required to reach water quality objectives.

Furthermore, criteria have been defined also for multiport diffuser discharges into rivers, which reduce acute impacts in the nearfield discharge region.

As an additional consequence for the practical implementation of the 'combined approach', it appears that water authorities in the future must make increased use of predictive models for water 
quality control. This concerns, on the one hand, mixing zone models that must be used for the validation and extension of measured data (beyond its spatial and temporal restrictions) for existing point sources as well as for the sanctioning of any new sources. On the other hand, general water quality models must be employed, especially for cases of heavy pollutant loadings through the interaction of multiple sources as well as additional diffuse sources.

Furthermore, the dischargers themselves will be aware of the water quality response of their discharge and may apply mixing technologies, such as offshore/offbank multiport diffuser installations, to avoid highly concentrated pollutant plumes along long distances in the water bodies.

\section{Acknowledgements}

The authors would like to thank the Middle East Desalination Research Center for its financial support and technical guidance. Furthermore, they are grateful that the European Desalination Society (EDS) sponsored their workshop activities.

\section{REFERENCES}

City of Carlsbad (2005) Precise Development Plan and Desalination Plant Project (EIR 03/05). California, USA, 2005.

EC (European Community) (2000) Water Framework Directive. Official Publication of the European Community, L327, European Parliament, Brussels.

EC (European Community) (2008) Directive 2008/105/EC on Environmental Quality Standards in the Field of Water Policy. European Parliament, Brussels.

Jirka GH (2004) Integral model for turbulent buoyant jets in unbounded stratified flows. Part 1: The single round jet. Environmental Fluid Mechanics 4(1): 1-56.

Jirka GH (2006) Integral model for turbulent buoyant jets in unbounded stratified flows. Part 2: plane jet dynamics resulting from multiport diffuser jets. Environmental Fluid Mechanics 6(1): 43-100.

Jirka GH (2008) Improved discharge configurations for brine effluents from desalination plants. Journal of Hydraulic Engineering 134(1): 116-120.

Jirka GH, Bleninger T, Burrows R and Larsen T (2004a) Management of point source discharges into rivers: where do environmental quality standards in the EC-water framework directive apply? International Journal of River Basin Management 2(3): 225-233.

Jirka GH, Bleninger T, Burrows R and Larsen T (2004b) Management of point source discharges into rivers: where do environmental quality standards in the new EC-water framework directive apply? International Journal of River Basin Management 2(3): 225-233.

Lattemann S and Höpner T (2003) Seawater Desalination: Impacts of Brine and Chemical Discharge on the Marine Environment. Desalination Publications, L'Aquila, Italy. Niepelt A, Bleninger T and Jirka GH (2008) Desalination brine discharge modeling. Coupling of hydrodynamic models for brine discharge analysis. Proceedings of an International Conference on Marine Waste Water Discharges - MWWD 2008, Cavtat, Croatia, ISBN 978-9944-5566-3-7.

Rutherford JC (1994) River Mixing. Wiley, Chichester.

Sánchez-Lizaso JL, Romero J, Ruiz J, et al. (2008) Salinity

tolerance of the Mediterranean seagrass Posidonia oceanica: recommendations to minimize the impact of brine discharges from desalination plants. Desalination 221: 602-607.

Sultanate of Oman (2005) Ministerial Decision No: 159/2005, Promulgating the bylaws to discharge liquid waste in the marine environment. Ministry of Regional Municipalities, Environment and Water Resources, Oman.

US EPA (US Environmental Protection Agency) (1994) Water Quality Standards Handbook, 2nd edn. US EPA, EPA 823-B94-005a, Washington, DC, USA.

US EPA (US Environmental Protection Agency) (2006) National Recommended Water Quality Criteria: 2006. See http:// nepis.epa.gov/Exe/ZyPURL.cgi?Dockey=P1003R9X.txt (accessed 18/02/2011).

Western Australia EPA (Environmental Protection Authority) (1993) Western Australian water quality guidelines for fresh and marine waters. Bulletin 711, October. See http:// www.epa.wa.gov.au/docs/1396_B711.pdf (accessed 18/02/2011).

Western Australia EPA (Environmental Protection Authority) (2002) Revised Environmental Quality Criteria Reference Document (Cockburn Sound). A supporting document to the draft Environmental Protection (Cockburn Sound) Policy 2002. Environmental Protection Authority Report. See http:// www.epa.wa.gov.au/docs/1567_EQCCS02R.pdf (accessed 18/02/2011).

World Bank Group (1998) Thermal Power: Guidelines for New Plants, from the Pollution Prevention and Abatement Handbook. See http://www.ifc.org/ifcext/enviro.nsf/Content/ EnvironmentalGuidelines (accessed 18/02/2011).

World Bank Group (2007) Environmental, Health, and Safety General Guidelines (EHS Guidelines). See http://www.ifc.org/ ifcext/enviro.nsf/Content/EnvironmentalGuidelines (accessed 18/02/2011).

\section{WHAT DO YOU THINK?}

To discuss this paper, please email up to 500 words to the editor at journals@ice.org.uk. Your contribution will be forwarded to the author(s) for a reply and, if considered appropriate by the editorial panel, will be published as a discussion in a future issue of the journal.

Proceedings journals rely entirely on contributions sent in by civil engineering professionals, academics and students. Papers should be $2000-5000$ words long (briefing papers should be 1000-2000 words long), with adequate illustrations and references. You can submit your paper online via www.icevirtuallibrary.com/content/journals, where you will also find detailed author guidelines. 